Nig. J. Pure \& Appl. Sci. Vol. 34 (Issue 2, 2021)
e-ISSN 2756-4045
Life Sciences, Univ. of Ilorin, Nigeria
www.njpas.com.ng

\title{
Detection of IgG Antibodies to Glycosylphosphatidylinositol (GPI) as a Biomarker of Immune Status to Plasmodium species
}

\author{
*A. Sani, M.H.I. Doko, and M.S. Aliyu
}

Page | 4178 Department of Microbiology, Faculty of Life Sciences, Ahmadu Bello University, Zaria, Nigeria

Date Received: 25-08-2021

Date Accepted: 15-11-2021

DOI: https://doi.org/10.48198/NJPAS/21.B12

\section{ABSTRACT}

Finding new ways to eliminate malaria is critical and this would greatly be influenced by developing indicators of exposure as well as distribution of effective vaccines against Plasmodium. This study was aimed at detecting Immunoglobulin G(IgG) antibodies, to glycosylphosphatidylinositol (GPI) as a biomarker of immune status to Plasmodium species. In this study, blood samples were gotten from apparently healthy individuals and patients having symptoms of malaria attending Ahmadu Bello University Teaching Hospital, Zaria. Thick and thin blood smears were prepared and stained with Giemsa stain. The smears were observed microscopically. Parasite densities were estimated on positive slides. Samples positive and some negative for Plasmodium were further tested to detect IgG antibodies to GPI among both the Asymptomatic and Symptomatic participants using ELISA. The prevalence of Plasmodium infection among both asymptomatic and symptomatic participants in this study was $18.9 \%$ and the prevalence of asymptomatic malaria was $15.6 \%$. There was a significant association between the level of parasitemia and concentration of IgG antibodies to GPI among the asymptomatic participants and a no significant association among symptomatic participants. Type of housing amongst other risk factors was the only factor significantly associated with malaria in this study. This study suggests PGPI as a biomarker of immunity to Plasmodium and may be a vaccine candidate for programs of malaria control.

Keywords: Plasmodium falciparum, glycosylphosphatidylinositol, vaccine, ELISA, IgG

\section{Introduction}

Malaria is caused by the parasitic protozoan Plasmodium. It remains one of the most debilitating infectious diseases, globally threatening nearly half of global population and leading to an estimated 400000 deaths yearly, predominantly among children in Africa. It is caused in humans by four species of single-cell, eukaryotic Plasmodium parasites; Plasmodium falciparum, Plasmodium vivax, Plasmodium ovale and Plasmodium malariae that are transmitted by the feeding of female Anopheles mosquitoes (Philips et al., 2017).

Malaria is a disease of poverty amongst other risk factors and has a major negative impact on

\section{Corresponding Author: Sani, A.}

Department of Microbiology, Faculty of Life Sciences, Ahmadu Bello University, Zaria, Nigeria

Phone: +2348106502875: Email: aminasani1992@gmail.com 
political, social and economic stability, and thereby hampers the development of developing human societies (Ricardo et al., 2014).210 million people were infected with Plasmodium in 2010 and 1.2 million people, primarily children, died from this Page | 4179 devastating disease (Ricardo et al., 2014). Plasmodium falciparum accounts for about twothirds of all malaria infections and 90-95\%of the infections that cause deaths in sub-Saharan Africa. Plasmodium vivax is responsible for infection in individuals living in deprived areas of Latin America and Asia where the disease has massive economic cost, although deaths not a substantial problem (Ricardo et al., 2014).

Further reduction in malaria prevalence and its elimination would be greatly influenced by the development of indicators of exposure and/or acquired immunity to malaria, as well as the distribution of effective vaccines against Plasmodium. A better knowledge of the acquisition of immunity in endemic populations is necessary for the identification of antigens useful as indicators, to inform rational vaccine development. After multiple Plasmodium infections, most naturally-exposed individuals in hyperendemic areas acquire natural acquired immunity and the main indicator of protection is the high level of disseminating merozoite-specific antibodies. After infection, hyper-immune individuals develop low parasitaemia and asymptomatic infection. The merozoite-specific antibodies are believed to cause host resistance to infection by preventing parasite invasion of RBCs, or by opsonizing infected RBCs and promoting phagocytosis and parasite elimination by macrophages (Ricardo et al.,2014). Further, studies in mice and humans show that both sporozoite-specific neutralizing antibodies and cytotoxic CD8+ T cells are important components of immune-mediated resistance to the hepatocytic stage of Plasmodium life cycle (Irene et al., 2014). However, sporozoite-specific immune responses contributing to natural acquired immunity or relevant to vaccine-induced protection is not clear. Studies have shown the mechanisms by which innate immunity affects the development of acquired immunity, but still elusive is the role the innate immune receptor in the process. (Irene et al., 2014). Studies have unveiled the complexity of innate immune receptors that function as sensors of malaria parasites and we are beginning to understand how they mediate host resistance to Plasmodium infection (Ricardo et al 2014).

Glycosylphosphatidylinositol (GPI) anchors most surface proteins to the protozoan plasma membrane and are important for the parasite viability. Essentially, protozoan GPI is a potent stimulators of cytokine synthesis by macrophages. This activity is determined by their fine structure, which includes the number and variation of carbohydrate units; the lipid inositol portion (glycerol versus ceramide); and the number, length and degree of saturation of the hydrocarbon chains (Craig et al., 2003). GPI anchors from $P$. falciparum merozoites have either two or three fatty acyl chains and trigger the phosphorylation of mitogen-activated protein kinases and inhibitor of nuclear factor- $\kappa \mathrm{B}$ (NF- $\kappa \mathrm{B})$ family members through the activation of TLR2-TLR6 or TLR1TLR2 heterodimers and, to a lesser extent, TLR4 homodimers. The activation of TLRs induces the production of nitric oxide and the synthesis of proinflammatory cytokines in mouse macrophages, such as TNF andIL-1 339 40. While, TLR activation by GPI anchors induces the expression of ICAM1, vascular cell adhesion molecule 1 (VCAM1) and E selectin, as well as the production of nitric oxide in human umbilical vascular endothelial cells (Craig et al., 2003).

The objectives of the study were to, detect Plasmodium in blood samples of apparently healthy individuals and malaria patients using microscopy, determine the level of parasitemia in the microscopy positive individuals and to detect and quantify $\mathrm{IgG}$ antibodies to Plasmodium Glycosylphosphatidylinositol (PGPI) using Enzyme Linked Immunosorbent Assay (ELISA). 


\section{Materials and Methods}

\section{Study Area}

The study was conducted in Zaria, Kaduna State, Nigeria. Zaria is an ancient city in northern Kaduna State, in Nigeria located on latitude $11^{\circ} 04^{\prime} 54^{\prime \prime} \mathrm{N}$ Page | 4180 and longitude $7^{\circ} 42^{\prime}$ '57' E (Oladimeji and Ojibo, 2012).

\section{Study Population}

The study population included apparently healthy male and non-pregnant female that consented and children $\geq 1$ year of age. There was a control group which comprised individuals with symptoms of malaria.

\section{Study Design}

The study was cross-sectional and hospital based, and convenient sampling was used to recruit the study participants.

\section{Sample Size}

For the purpose of this study, a prevalence rate of $14.1 \%$ as reported from a study conducted in Zaria, Kaduna State, Nigeria (Inabo et al., 2011) was used to determine the sample size. Using the equation below, at 95\% confidence interval. A total of 207 blood samples were collected for this study.

\section{Sample Collection and Processing}

A total of $5 \mathrm{mls}$ blood sample was collected aseptically into Ethylenediaminetetraacetic acid (EDTA) containers from the participants under study. Samples collected were transported in cold packs to the Department of Microbiology, Faculty of Life Sciences, Ahmadu Bello University, Zaria for analysis. Thick and thin blood films were made on clean - grease free slides. The smears were stained using $2 \%$ Giemsa solution for the thick film and thin film for the identification and speciation of the parasite respectively. A slide was negative if no Plasmodium parasite (having blue chromatin dot and pinkish-red cytoplasm, thin or thick) was found after scanning 100 high power fields. The parasites count was against one hundred white blood cells. A white cell count of $8000 / \mu 1$ was used in the analysis.

The parasite density was estimated using the formular below: -

Number of parasites per ul of blood

$=\underline{\mathrm{WBC} \text { count }(8000) \times \text { Parasites counted against } 100 \mathrm{WBC}}$

Number of white Blood Cells Counted

\section{Assay for PfGPI Antibody}

This was carried out using Enzyme Linked Immunosorbent Assay (ELISA) according to manufacturer's (Shanghai Coon Koon Biotech Co., Ltd in China) procedure. Optical density was read at $450 \mathrm{~nm}$ with microtitre plate reader within 10minutes. The concentration of $\mathrm{IgG}$ was classified as moderate $(300-600 \mathrm{mg} / \mathrm{dL})$, significant $(100-299 \mathrm{mg} / \mathrm{dL})$ or reduced $(<100 \mathrm{mg} / \mathrm{dL})$ as described by Shradha et al. (2007) which states the total level of $\operatorname{IgG}$ could be mild-moderate, significant and profoundly reduced.

\section{Data Analysis}

Data obtained from the result was analyzed using Chi-square for association of malaria to sociodemographic factors and risk factors with $\mathrm{P}$ at 0.05 as significant level and the association between level of parasitemia and concentration of $\mathrm{IgG}$ to GPI was analyzed using Spearman correlation all using SPSS software version 23. All data were summarized in tables and figures.

\section{Results}

A total of two hundred and seven individuals (207) were sampled in two groups of (53) fifty-three (25.6\%) symptomatic individuals and (154) one hundred and fifty-four (74.4\%) asymptomatic individuals.

Out of the two hundred and seven (207), thirty-five (35) tested positive, giving an overall prevalence of $16.9 \%$, the result is as shown in Figure 1. Of the one hundred and fifty-four (154) asymptomatic participants, twenty-four (24) were positive giving 
a prevalence of $15.6 \%$, as shown in Figure 2 and eleven (11) out of the fifty-three (53) symptomatic were positive with a percentage prevalence of $20.8 \%$, as shown in Figure 3.

Page | 4181 Table 1 shows the number of participants who fall between low, intermediate and high level of parasitemia among both asymptomatic and symptomatic participants. One (1) participant among the asymptomatic had low parasitemia and twenty-three (23) had intermediate parasitemia. Among the symptomatic, nine (9) participants had intermediate parasitemia and two (2) had high parasitemia. The highest level of parasitemia was recorded as 13000 parasites/ul among the symptomatic and the lowest level of parasitemia was 95.62 parasites/ul among the asymptomatic participants. The range of parasitemia among the asymptomatic participants was between 95.629931 parasites/ul and among the symptomatic was 489-13000 parasites/ul.

Table 2 shows the concentration of IgG to GPI among the participants. From the Table, thirty-on e (31) of the thirty-five (35) positive participants had low IgG concentration while two (2) each had moderate and significant concentrations respectively. Also, of the thirty-one (31) Plasmodium positive participants who had low IgG concentration, twenty (20) were from the asymptomatic while eleven (11) were from the symptomatic, and all the two (2) each of the moderate and significant IgG concentrations were of the symptomatic group of the participants.

Figure 4 shows that level of parasitemia decreases with an increase in concentration of IgG to GPI among asymptomatic participants. Using Spearman correlation Table 3 shows the relationship between the level of Parasitemia and concentration of $\operatorname{IgG}$ to GPI among the asymptomatic. The value of significance (significant when positive and not significant when negative) 0.1688 is before the +1 mark signifying a positive association. The correlation between the level of parasitemia and concentration of IgG to GPI was therefore significant among the asymptomatic.

The participants among the symptomatic had profoundly low concentrations of IgG. One (1) symptomatic participant who tested negative for Plasmodium infection had a significant concentration of IgG to GPI of $205.24 \mathrm{mg} / \mathrm{dl}$. Fig. 5 shows that the level of parasitemia decreases with an increase in concentration of IgG to GPI. Using Spearman correlation Table 4 shows the relationship between the level of parasitemia and concentration of IgG to GPI among symptomatic this shows there is negative correlation since the significance value, -0.1039 falls before the 0 mark. The correlation between the level of parasitemia and concentration of IgG to GPI is not significant among the symptomatic participants

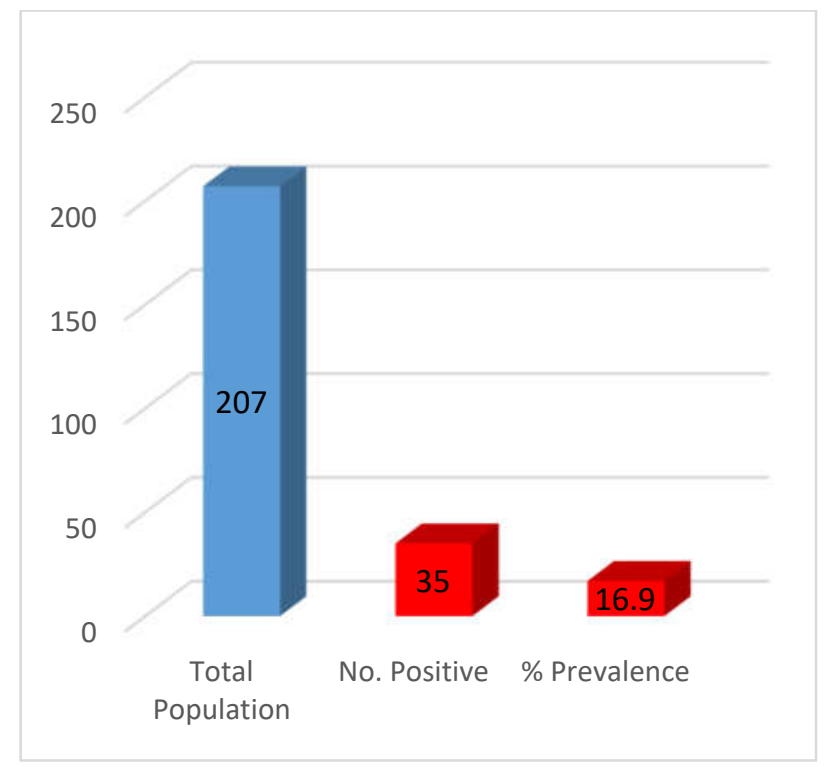

Figure 1: Total prevalence of plasmodium infection among all participants 


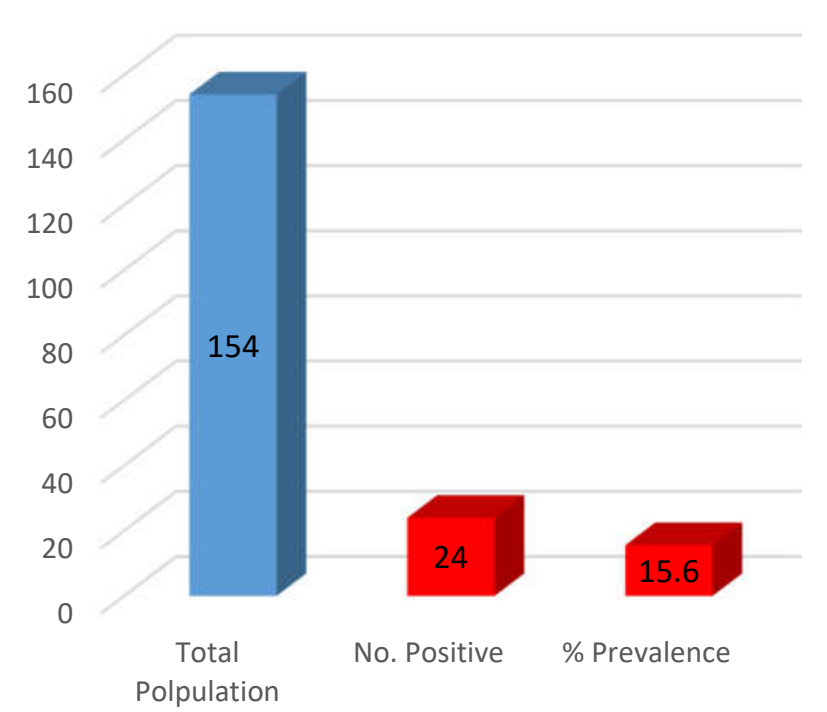

Figure 2: Prevalence of plasmodium infection among asymptomatic participants

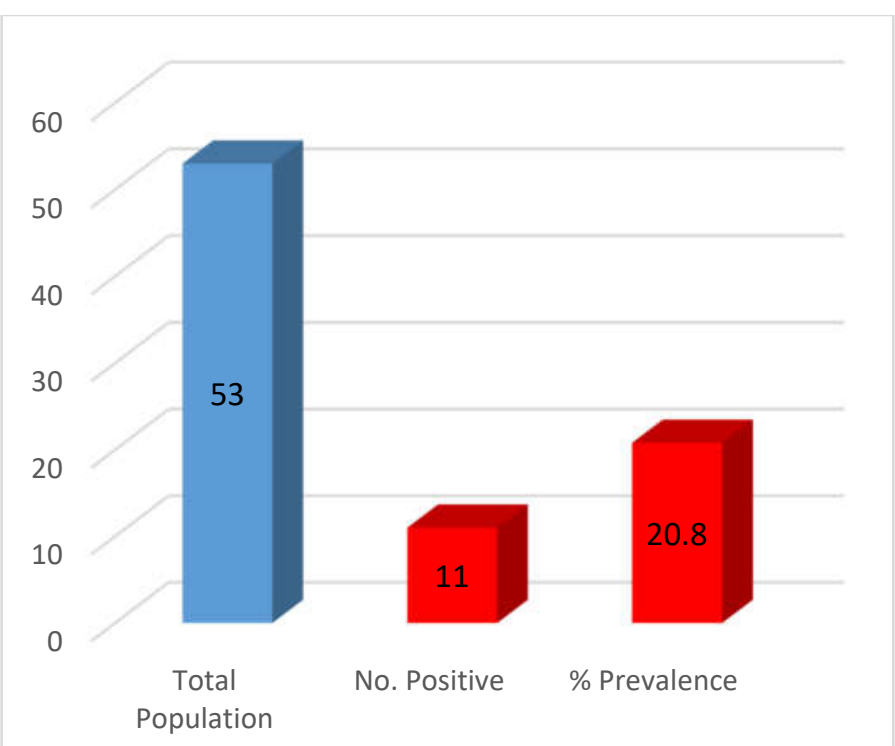

Figure 3: Prevalence of plasmodium infection among symptomatic participants

Table 1: Level of parasitemia among asymptomatic and symptomatic participants $(n=35)$

\begin{tabular}{lccc}
\hline Level of parasitemia & $\begin{array}{l}\text { Asymptomatic } \\
\text { No. of Samples }\end{array}$ & $\begin{array}{l}\text { Symptomatic } \\
\text { No. of Samples }\end{array}$ & Total \\
\hline Low & 1 & - & 1 \\
Intermediate & 23 & 9 & 32 \\
High & - & 2 & 2 \\
Total & 24 & 11 & 35
\end{tabular}

Low: $\mathrm{PD} \leq 100$ parasites/ul Intermediate: $100<\mathrm{PD}<10,000$ parasites/ul High: $\mathrm{PD} \geq 10,000$ parasites/ul.

Table 2: Concentration of IgG to GPI among asymptomatic and symptomatic participants $(\mathrm{n}=35)$

\begin{tabular}{llll}
\hline Concentration of IgG & $\begin{array}{l}\text { Asymptomatic } \\
\text { No. of Samples }\end{array}$ & $\begin{array}{l}\text { Symptomatic } \\
\text { No. of Samples }\end{array}$ & Total \\
\hline
\end{tabular}

\begin{tabular}{lccc}
\hline Low & 20 & 11 & 31 \\
Significant & 2 & - & 2 \\
Moderate & 2 & - & 2 \\
Total & 24 & 11 & 35 \\
\hline
\end{tabular}

Low Concentration: $>100 \mathrm{mg} / \mathrm{dl} \quad$ Significant Concentration:100-299mg/dl $\quad$ Moderate Concentration $300-600 \mathrm{mg} / \mathrm{dl}$ 


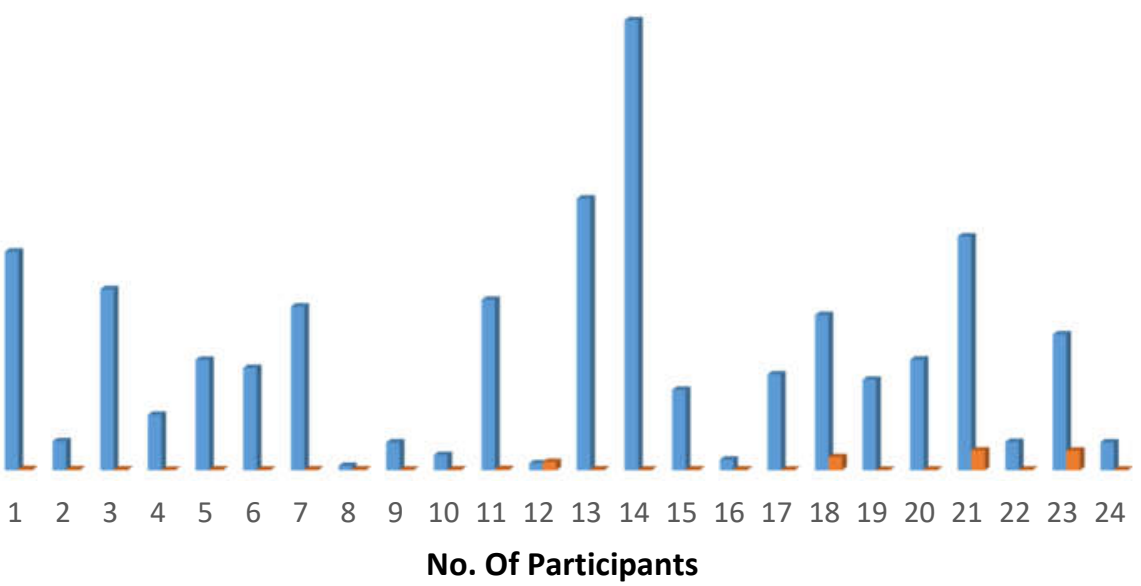

- LEVEL OF PARAS. $\quad$ CONCENTRATION

Figure 4: Association between Level of Parasitemia and Concentration of IgG to GPI among asymptomatic participants

Table 3: Correlation between Level of Parasitemia and Concentration of IgG to GPI Among Asymptomatic Participants

\begin{tabular}{lll}
\hline & $\begin{array}{l}\text { Level of } \\
\text { parasitaemia }\end{array}$ & $\begin{array}{l}\text { Concentration of } \\
\operatorname{IgG}\end{array}$ \\
\hline Level of parasitaemia & 1 & 1 \\
Concentration of IgG & & \\
\hline
\end{tabular}



Figure 5: Association between level of parasitemia and concentration of IgG to GPI among symptomatic participants 
Table 4: Correlation between Level of Parasitemia and Concentration of IgG to GPI among Symptomatic Participants

\begin{tabular}{lll}
\hline & $\begin{array}{l}\text { Level of } \\
\text { parasitaemia }\end{array}$ & $\begin{array}{l}\text { Concentration } \\
\text { of IgG }\end{array}$ \\
\hline Level of parasitaemia & 1 & 1 \\
Concentration of IgG & & \\
\hline
\end{tabular}

\section{Discussion}

The prevalence of malaria in this study was $16.9 \%$. This could show that malaria prevalence is gradually declining, as compared to the prevalence reported by Idoko et al. (2015); 46.5\%, Benjamin et al. (2016); 28.3\% and Okogwu et al. (2018); 25.3\% each in Kaduna State. The prevalence of asymptomatic malaria in this study was $15.6 \%$. This is to show that the incidence of asymptomatic malaria is also gradually reducing. This is lower than that reported by Osue et al. (2013); which was $20.5 \%$ in a work carried out in Kaduna State.

There was significant correlation between level of parasitemia and concentration of $\mathrm{IgG}$ to GPI among the asymptomatic. From the result it was observed that a high parasitemia was correlated to a low concentration of IgG to GPI and vice versa. This is in agreement with the report of Craig et al. (2003) which states that there is an association between concentration of IgG to GPI and level of parasitemia. And among the symptomatic participants, there was no correlation between level of parasitemia and concentration of IgG to GPI. This indicates that the presence of high IgG to GPI reduces the number of parasites and with low IgG to GPI the organism can move into the erythrocytic stage and multiply producing more parasites.

This could also indicate that IgG to GPI has a role to play in the immunity to Plasmodium falciparum at the erythrocytic stage also confirming this is the lack of association between the level of parasitemia and concentration of $\operatorname{IgG}$ to GPI among the symptomatic participants this is in agreement as reported by Craig et al. (2003), Franc et al.(2017) and Camilla et al.(2017) which states GPI as a biomarker of immunity to Plasmodium falciparum.

\section{Conclusion}

The prevalence of malaria was $16.9 \%$, asymptomatic parasitemia was $15.6 \%$ and symptomatic malaria was $20.8 \%$ among the study population. The level of parasitemia decreased with an increase in IgG to GPI. This study shows that there is a positive correlation between the level of parasitemia and concentration of $\mathrm{IgG}$ to GPI indicating that the presence of IgG has an effect in reducing the level of parasitemia. This highlights anti-PfGPI as a biomarker of immunity to malaria therefore a vaccine candidate for control programs of malaria.

\section{References}

Benjamin, M.J., Mary, S., Lina, L., Samuel, M., Peter, S., Leanne, J.R., Ivo, M and Timothy, M.E. (2016). Risk Factors for Plasmodium vivax Gametocyte Carriage in Papua New Guinean children with Uncomplicated Malaria. Acta Tropica JournalElsevier.160:1-8

Camilla, T.F., Connie, S.N., Amandaine, C., Peter, S., Ivo, M. (2017). IgG Antibodies to Synthetic GPI are Biomarkers of Immune 
Status to both Plasmodium falciparum and Plasmodium vivax Malaria in Young Children. Malaria Journal. 16(386):1-10.

Craig, B., Peter, K. F., Channe, C., Moses, L., Page | 4185 Charles, S.M., Moses, J. B., Nicholas, M.A. (2003). Immunoglobulin G (IgG) Responses to Plasmodium falciparum Glycosylphosph atidylinositol Are Shortlived and Predominantly of the IgG3 subclass. The Journal of Infectious Disease. 187; 962-5.

Franc, C., Niu, G., Zhang, G., Roobsong, W., Wang, N., Xiaohong, W., Prachumsri, J., Noah, S.B and Li, J. (2017). The Fibrinogenlike Domain of FREP1 Protein is a Broad Spectrum Malaria Transmission Blocking Vaccine Antigen. Journal of Biological Chemistry.292 (28), 11960-11969.

Idoko, M.O., Ado, S.A and Umoh, V.J. (2015). Prevalence of Dengue Virus and Malaria in Patients with Febrile Complaints in Kaduna Metropolis, Nigeria. Microbiology Research Journal International. 8(1):343- 347

Inabo, H.I and Umaru, B.Z. (2011). Studies on Incidence of Asymptomatic Plasmodium Infection among Apparently Healthy Subjects in Orphanages in Kaduna and Zaria, Nigeria. Bayero Journal of Pure and Applied Sciences. 4: 83-86.

Irene, P.M., Romeo-Karl, I.L., Nina, T.M., Auguston-Ghislain, M.O., Fousseyni, S.T. (2017). High Level of Specific Anti Plasmodium falciparium Merozoite IgG Antibodies In Rural Asymptomatic Individuals of Dienga, South- eastern
Gabon. European Journal of Microbiology and Immunology.7(4):247-260.

Okogwu, S., Uhunmwangho, E.J., Garba, D.D., Emelike, O.F and Amaechi, R. (2018). Prevalence of Malaria Parasite among Patients Attending Some Selected Health Institutions in Kaduna State, Nigeria. Scholars journals of Applied Medical Science.6 (11): 4568-4576

Oladimeji, J.S and Ojibo S.D. (2012). Governoance Perception of Informal Enterprise Operators in Zaria, Nigeria. American International Journal of Contemporary Research.2(10): 150- 159.

Osue, H.O., Inabo, H.I., Yakubu, S.E., Audu, P.A., Galadima, M., Odama, L.E., Musa, D., Ado, S.A and Mamman, M. (2013). Impact of Eighteen-Year Varied Compliance Treatment withIvermectin in Sentinel Savannah Agrarian Communities in Kaduna State of Nigeria.International Scholarly Research Notices Parasitology.1-10.

Philips, A.M, Jeremy, N.B., Christiane, M., Rob, H.V., Wesley, C.V., Timothy, N.C. (2017). Malaria.

Ricardo, T.G., Palisa, K., Katherine, A.F., Douglas, T.G. (2014). Innate Sensing of Malaria Parasites. Nature Reviews Immunology. 14(11):744-57.

Shradha, A. and Charlotte, C. (2007). Assessment and Clinical Interpretation of Reduced IgG Values. Ann Allergy Asthma Immunology. 99(3):281-283s 